\title{
Research
}

Paper

\section{Antihistaminic and antianaphylactic activity of HK-07, a herbal formulation}

\author{
S. Gopumadhavan, Mohamed Rafiq, M.V. Venkataranganna, S.K. Mitra
}

R\&D Center, The Himalaya

Drug Company,

Bangalore-562 123. India

Received: 26.3.2005

Revised: 11.7.2005

Accepted: 13.7.2005

Correspondence to:

S.K. Mitra

E-mail:

research@himalayahealthcare.com

\begin{abstract}
Objective: To study the antianaphylactic, antihistaminic and mast cell stabilization activity of HK-07 in experimental animals.

Materials and Methods: HK-07 is a polyherbal formulation containing extracts of various plant constituents. The compound HK-07 was evaluated using Wistar rats and Duncan Hartley guinea pigs. The antianaphylactic activity was investigated in rats using the active anaphylaxis model. The effect on mast cell stabilization was performed by ex vivo challenge of antigen in sensitized rat intestinal mesenteries. Antihistaminic activity was studied in guinea pigs using histamine-induced bronchospasm where preconvulsive dyspnea was used as an end point following exposure to histamine aerosol. Dose response studies of HK-07 were conducted at 125,250 , and $500 \mathrm{mg} / \mathrm{kg}$, p.o. in anaphylactic shock-induced bronchospasm in rats. The optimal dose level was used for the remaining experimental models.

Results: Treatment with HK-07 at 125, 250, and $500 \mathrm{mg} / \mathrm{kg}$, p.o. showed significant reduction in signs and severity of symptoms $(P<0.05)$, onset $(P<0.001)$ and mortality rate $(P<0.05)$ following anaphylactic shock-induced bronchospasm. HK-07 also significantly reduced the serum IgE levels $(P<0.001)$ in animals compared to untreated controls. Treatment of sensitized animals with HK-07 at $500 \mathrm{mg} / \mathrm{kg}$, p.o. for 2 weeks resulted in a significant reduction in the number of disrupted mast cells $(\mathrm{P}<0.001)$ when challenged with an antigen (horse serum). HK-07 significantly prolonged the latent period of convulsion $(P<0.008)$ as compared to control following exposure of guinea pigs to histamine aerosol.

Conclusion: The findings from various studies reveal that the antihistaminic and antianaphylactic activity of HK-07 may be due to the mast cell stabilizing potential, suppression of $\lg \mathrm{E}$, and inhibition of release of inflammatory mediators.
\end{abstract}

KEY WORDS: Hypersensitivity, IgE, mast cell degranulation.

\section{Introduction}

Allergy is one of the common diseases that affect mankind with diverse manifestations. The prevalence of allergy and asthma has risen in the recent years despite an improvement in the general health of the population. ${ }^{[1]}$ Allergic diseases are responsible for significant morbidity and have severe economic impact. ${ }^{[2]}$ Various epidemiological studies have identified the causes for an increase in the prevalence of upper and lower respiratory tract allergic diseases. Some of the postulated reasons are increasing environmental pollution ${ }^{[3]}$ and increased predisposition of individuals producing excessive IgE through a major change in the gene pool, changing lifestyles, and an increasing awareness of the disorders. ${ }^{[4]}$
Intensive research during the last several decades has highlighted the role of lymphocytes, immunoglobulins, mast cells, and various autacoids in the etiopathogenesis of allergic conditions. Inspite of the voluminous literature on the subject, the treatment of allergic diseases continues to be far from satisfactory. The available treatment options for upper and lower respiratory tract allergic diseases have major limitations owing to low efficacy, associated adverse events, and compliance issues. ${ }^{[5]}$

Ayurveda, an Indian system of medicine, has described several drugs from indigenous plant sources for use in the treatment of bronchial asthma and allergic disorders. HK-07 is one such polyherbal formulation containing mainly the extracts of Curcuma longa, Zingiber officinale, Piper longum, 
Emblica officinalis, Terminalia belerica, Ocimum sanctum, Adhatoda vasica, and Cyperus rotundus. The dry rhizome of Curcuma longa contains curcumin, the main bioactive component, demethoxycurcumin, and bisdemethoxycurcumin. The traditional uses of turmeric or natural curcuminoids in folk medicine are multiple, and some are based on their antioxidant, antiinflammatory and antiallergic properties which have been confirmed by various experimental studies. ${ }^{[6]}$ Curcumin is also found to be a potent blocker of nuclear transcription factor (NF)-kB, ${ }^{[7]}$ which is linked to a variety of diseases including allergy and asthma. ${ }^{[8]}$ Ocimum sanctum has been demonstrated to protect against histamine, as well as pollen-induced bronchospasm in guinea pigs and inhibited antigen-induced histamine release from sensitized mast cells ${ }^{[9]}$ apart from its established antiinflammatory ${ }^{101}$ and antioxidant ${ }^{1111}$ properties. Adhatoda vasica is documented for its potent antiinflammatory, ${ }^{\mid 12]}$ antiallergic, and antitussive activities. ${ }^{[13]}$ Piper longum has been shown to reduce the passive cutaneous anaphylaxis in rats and protect guinea pigs against antigen-induced bronchospasm. ${ }^{[14]}$ Emblica officinalis was found to exhibit antiinflammatory, antitussive and antioxidant activities. ${ }^{[15,}{ }^{16]}$ Terminalia belerica demonstrated potent antiperoxidative activity and inhibited lipid peroxide formation by scavenging hydroxyl and superoxide radicals in vitro. ${ }^{[17]}$ Zingiber officinale has been found to exert anti-inflammatory activity and is reported to be a potent inhibitor of inflammatory mediators such as prostaglandins and leukotrienes. ${ }^{[18]}$ Cyperus rotundus inhibited the nitric oxide and superoxide production in in vitro studies, which used murine macrophage cell lines. ${ }^{[19]} \mathrm{HK}-07$ was found to be clinically effective and safe in children suffering from upper and lower respiratory tract infections. ${ }^{|20|}$

In the present study, the effect of HK-07, a polyherbal formulation was studied on the active anaphylaxis and mast cell stabilization in rats, and histamine-induced bronchospasm in guinea pigs.

\section{Materials and Methods}

\section{Animals}

Inbred Wistar rats (175-200 g) and guinea pigs (400-600 g) of either sex housed in standard conditions (temperature $22 \pm 2{ }^{\circ} \mathrm{C}$, relative humidity $60 \pm 5 \%$ and $12 \mathrm{~h} \mathrm{light/dark}$ cycle) were used. They were fed with standard pellet diet and water ad libitum. The Institutional Animal Ethics Committee approved the experimental protocol. All the animals received humane care according to the criteria outlined in the "Guide for the Care and Use of Laboratory Animals" prepared by the "National Academy of Sciences" and published by the "National Institute of Health".

Histamine and horse serum were procured from Sigma Chemicals and toluidine blue from Loba-Chemie, Mumbai. Elisa kit for IgE was supplied by Orion diagnostics, Espoc, Finland. All other chemicals and reagents were procured from Hi-Media Laboratories limited, Mumbai.

Active anaphylaxis

Twenty-eight rats were sensitized by injecting subcutaneously $0.5 \mathrm{ml}$ of horse serum along with $0.5 \mathrm{ml}$ of triple antigen containing 20,000 million Bordetella pertussis organisms (Serum Institute of India Ltd., Pune, India). The sensitized rats were divided into 4 groups of 7 each. Group I served as control and received water (vehicle). Groups II, III and IV were administered HK-07 at 125, 250, and $500 \mathrm{mg} / \mathrm{kg}$ respectively, orally, once a day for 14 days. On day 14, after 2 $\mathrm{h}$ of treatment, the rats were challenged with intravenous injection (tail vein) of $0.25 \mathrm{ml}$ horse serum in normal saline. They were then observed for the onset of symptoms such as dyspnea and cyanosis, duration of the persistence of symptoms (min), and mortality. The severity of symptoms was scored. ${ }^{[21]}$ The optimal pharmacological effective dose of HK-07, which is derived from this dose response study was used for the remaining studies.

Serum total IgE was quantified with an ELISA protocol according to the manufacturer's instructions. Briefly, the plates were coated with affinity-purified rabbit anti IgE overnight at $4{ }^{\circ} \mathrm{C}$ and then blocked with $1 \%$ bovine serum albumin (BSA) in phosphate buffered saline (PBS) for $1 \mathrm{~h}$ at $37^{\circ} \mathrm{C}$. The serum samples and appropriate dilutions of a standard $\operatorname{IgE}$ preparation were placed in the wells, and the plates were incubated for $3 \mathrm{~h}$ at $4{ }^{\circ} \mathrm{C}$. Sample blank wells were treated similarly but without serum. The bound IgE was detected with polyclonal goat anti IgE antibodies (incubation for $1 \mathrm{~h}$ at 37 ${ }^{\circ} \mathrm{C}$ ), followed by HRP-conjugated rabbit anti-goat antibodies (incubation for $1 \mathrm{~h}$ at $37^{\circ} \mathrm{C}$ ). The plates were developed by the addition of O-phenylene diamine and read in an ELISA (Anthos HT-II, USA) plate reader at $490 \mathrm{~nm}$.

\section{Mast cell stabilizing activity}

Thirty-two rats were divided into four groups of eight animals in each group. Group I served as control and received vehicle (water). Group II (sensitized control group, received only water), Groups III (HK-07) and IV (prednisolone) were sensitized by injecting $0.5 \mathrm{ml}$ of horse serum subcutaneously along with $0.5 \mathrm{ml}$ of triple antigen containing 20,000 million Bordetella pertussis organisms (Serum Institute of India Ltd., Pune). Group III were administered HK-07 $500 \mathrm{mg} / \mathrm{kg}$, p.o., once a day for 14 days. Group IV were administered prednisolone (reference drug) $10 \mathrm{mg} / \mathrm{kg}$, p.o., for the same duration. On day 14, the rats were sacrificed $2 \mathrm{~h}$ after the treatment and the intestinal mesentry was taken out for the study on mast cells. Mesentries along with intestinal pieces were excised and kept in Ringer Locke solution (NaCl 154, KCl $5.6, \mathrm{CaCl}_{2} 2.2, \mathrm{NaHCO}_{3} 6.0$, glucose $5.55 \mathrm{mM} / \mathrm{L}$ of distilled water) at $37^{\circ} \mathrm{C}$. The mesenteric pieces were challenged with $5 \%$ horse serum for $10 \mathrm{~min}$ after which the mast cells were stained with $1.0 \%$ toluidine blue and examined microscopically for the number of intact and degranulated mast cells. ${ }^{\mid 211}$

\section{Histamine-induced bronchospasm in guinea pigs}

Bronchospasm was induced in guinea pigs by exposing them to $1 \%$ histamine aerosol under constant pressure $(1 \mathrm{~kg} /$ $\left.\mathrm{cm}^{2}\right)$ in an aerosol chamber $(24 \times 14 \times 24 \mathrm{~cm})$ made of perplex glass. Of the two groups of six animals each, Group I served as control and Group II received HK-07 $500 \mathrm{mg} / \mathrm{kg}$, p.o., once a day for 5 days. The animals were exposed to $1 \%$ histamine aerosol under constant pressure $\left(1 \mathrm{~kg} / \mathrm{cm}^{2}\right)$ in an aerosol chamber on day 0 without any treatment. The end point, preconvulsive dyspnea (PCD) was determined from the time of aerosol exposure to the onset of dyspnea leading to the appearance of convulsions. ${ }^{[22]}$ As soon as PCD commenced, the animals were removed from the chamber and exposed to 
fresh air. This PCD was taken as day 0 value. On days 1 and 5, $2 \mathrm{~h}$ after the administration of the drug, the time for the onset of PCD was recorded as on day 0.

Statistical analysis

The results of various studies were expressed as mean \pm SEM and analyzed statistically using one-way ANOVA, followed by Bonferroni's multiple comparison post-hoc test or Chisquare test or unpaired Student's ' $t$ ' test to find out the level of significance. $\mathrm{P}<0.05$ was considered statistically significant. The analysis was performed using Graphpad Prism software package (Version 4.0).

\section{Results}

Effect of HK-07 on anaphylactic shock-induced bronchospasm in sensitized rats

HK-07 protected the sensitized rats against anaphylactic shock in a dose-dependent manner. In control rats, intravenous antigen challenge (horse serum) caused shock in $100 \%$ of the animals, while in treated rats $(500 \mathrm{mg} / \mathrm{kg}$ of HK-07), the onset of symptoms of shock was delayed $(\mathrm{P}<0.001)$, and symptoms were less severe $(\mathrm{P}<0.05)$ with reduced mortality $(\mathrm{P}<0.05)$ [Figure 1]. HK-07 $(500 \mathrm{mg} / \mathrm{kg})$ also resulted in significant reduction of serum IgE levels $(25.80 \pm 4.85 \mathrm{ng} / \mathrm{ml}, \mathrm{P}<0.001)$ as compared to sensitized controls $(125.06 \pm 9.66 \mathrm{ng} / \mathrm{ml})$. Serum IgE levels in control group was $8.83 \pm 0.84 \mathrm{ng} / \mathrm{ml}(\mathrm{P}$ $<0.001$ as compared to sensitized control). HK07 showed optimal pharmacological effect at $500 \mathrm{mg} / \mathrm{kg}$ dose. Hence, this dose of HK-07 was used for the remaining studies.

Mast cell stabilizing potential of HK-07

Antigen challenge resulted in significant degranulation of the mesentric mast cells (approximately 88\%, $\mathrm{P}<0.001$ ). Pretreatment of sensitized animals with HK-07 at $500 \mathrm{mg} / \mathrm{kg}$, p.o., for 2 weeks resulted in a significant reduction in the number of disrupted mast cells $(\mathrm{P}<0.001)$ when challenged with horse serum. The effect of HK-07 was also comparable with the reference drug prednisolone [Table 1].
Table 1

Effect of HK-07 on mast cell stabilization in sensitized rats

\begin{tabular}{|c|c|c|c|}
\hline \multirow{2}{*}{ Groups } & & \multicolumn{2}{|c|}{ Mast cells (\%) } \\
\hline & & Intact & Disrupted \\
\hline \multicolumn{2}{|l|}{ Control } & $83.06 \pm 3.70^{*}$ & $16.94 \pm 3.70^{*}$ \\
\hline \multicolumn{2}{|c|}{ Sensitized control } & $12.31 \pm 1.92$ & $87.69 \pm 1.92$ \\
\hline \multicolumn{2}{|c|}{ HK-07 (500 mg/kg) } & $64.25 \pm 9.51^{*}$ & $35.75 \pm 9.51^{*}$ \\
\hline \multicolumn{2}{|c|}{ Prednisolone $(10 \mathrm{mg} / \mathrm{kg})$} & $69.19 \pm 4.89^{*}$ & $30.81 \pm 4.89^{*}$ \\
\hline One-way & $\mathrm{F}$ & 129.7 & 129.7 \\
\hline \multirow[t]{2}{*}{ ANOVA } & $\mathrm{df}$ & 31 & 31 \\
\hline & $\mathrm{P}$ & 0.0001 & 0.0001 \\
\hline
\end{tabular}

Values are mean $\pm S E M, n=8$ in each group. *Significantly different from sensitized control ( $\mathrm{P}<0.001)$, (Bonferroni's multiple comparison post-hoc test).

Figure 2. Effect of HK-07 on histamine induced bronchospasm in guinea pigs.

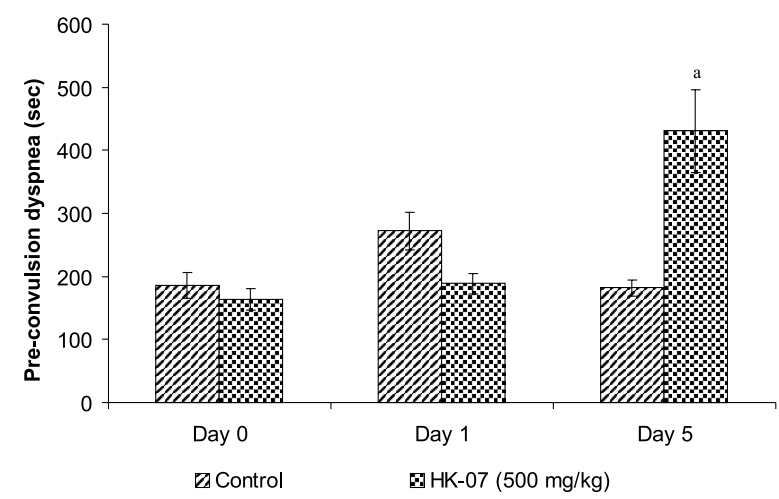

Values are expressed as mean $\pm S E M ; n=6$ in each group. ${ }^{a}<<0.008$ as compared to control on Day 5 (unpaired Student's ' $t$ ' test).

Figure 1. Effect of HK-07 on anaphylactic shock-induced bronchospasm in rats.

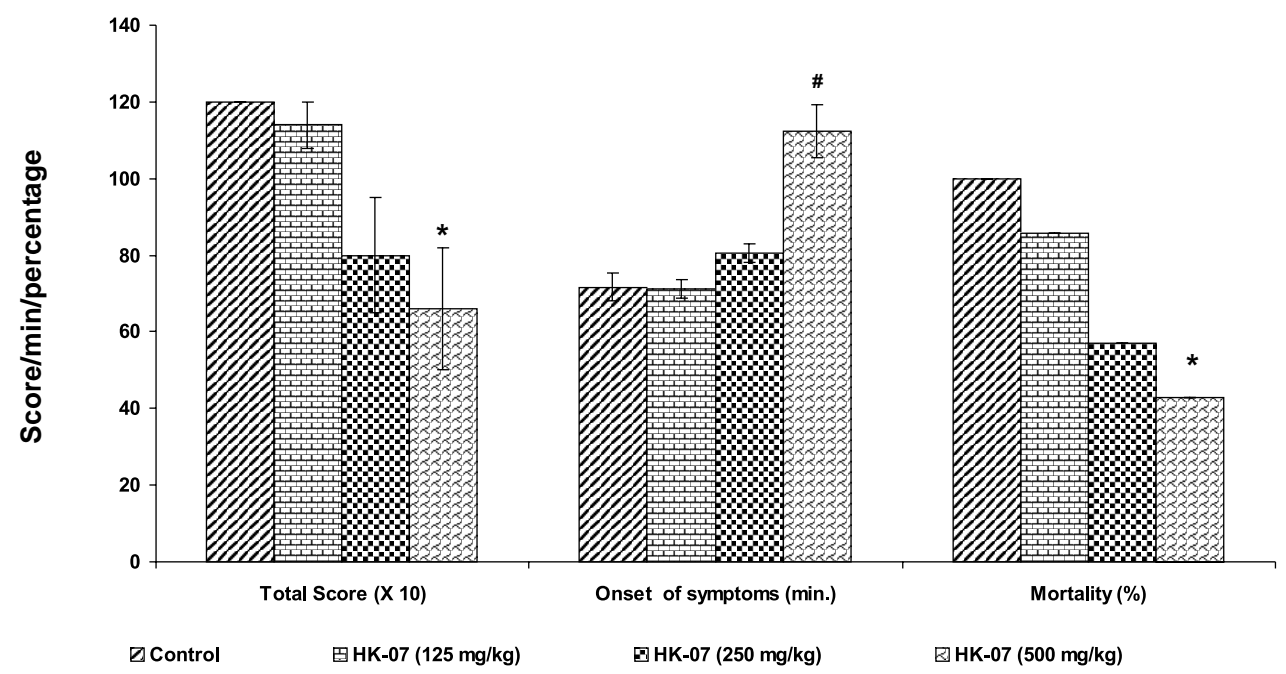

Values are expressed as mean \pm SEM except for mortality, which is expressed as percentage, $n=7$ in each group; Total score: $F=5.508$, $d f=27$, $\mathrm{P}=0.0050$; Onset of symptoms: $\mathrm{F}=20.51, \mathrm{df}=27, \mathrm{P}=0.0001$. ${ }^{\star} \mathrm{P}<0.05$, \#P<0.001 as compared to control. (ANOVA followed by Bonferroni's multiple comparison post hoc test for total score and onset of symptoms. Chi-square test for mortality). 


\section{Effect on histamine-induced bronchospasm}

HK-07 at $500 \mathrm{mg} / \mathrm{kg}$, p.o., significantly prolonged the latent period of PCD ( $\mathrm{P}<0.008)$ as compared to control, following exposure to histamine aerosols on day 5 [Figure 2].

\section{Discussion}

Experimental animal model of asthma is characterized by allergen-induced immediate airway constriction and late airway reactivity to a pharmacological vasoconstrictor such as histamine and leukotrienes. Histamine is a central mediator in the pathogenesis of allergic and inflammatory disorders. In the present study, HK-07 prolonged the latent period of PCD in guinea pigs following histamine aerosol. This may be suggestive of an antihistaminic activity following treatment with HK07. It also offered protection against anaphylactic shock-induced bronchospasm in rats.

Basophils, mast cells, and their preformed de novo synthesized mediators, play a pivotal role in the pathogenesis of allergic disorders. These molecules are potent vasoactive and bronchoconstrictor agents and they modulate local immune responses and inflammatory cell infiltration. ${ }^{23,}{ }^{241}$ Immunoglobulin E (IgE)-mediated mast-cell stimulation is an important initial event in the development of type I allergic reactions such as asthma and atopic disorders. Clinical studies have found a close association between asthma and serum IgE levels, as well as IgE-dependent skin test reactivity to allergens. ${ }^{\mid 25]}$ Antigen challenge, in sensitized animals, results in the degranulation of mast cells, which is an important feature of anaphylaxis. In the present study, HK-07 showed marked protection against the mast cell degranulation following antigen challenge in sensitized animals. Mast cell stabilizing activity of HK-07 may be attributed to the presence of herbal extracts, which are known for their mast cell stabilizing potential against antigen-antibody reaction and/or due to the suppression of IgE antibody production, which is responsible for degranulation mast cells. ${ }^{191}$ This antianaphylactic and antihistaminic effect may be caused by the stabilization of the mast cell membrane, suppression of IgE, and inhibition of pathological effects induced by the release of inflammatory mediators in HK-07 treated animals.

All the above findings lend credence to the beneficial use of HK-07 in the treatment of asthma and related conditions. However, further studies with other experimental models, especially to explore the role of cytokines are warranted to substantiate the antiasthmatic and antiallergic activity of HK07.

\section{References}

1. Ring J, Kramer U, Shafer T, Beherendt $\mathrm{H}$. Why are allergies increasing? Curr Opinions Immunol 2001;13:701-8.

2. Spector SL. Overview of comorbid associations of allergic rhinitis. J Allergy Clin Immunol 1997;99:773-80.

3. Passali D, Lauriello M, Mezzedimi C, Bellussi L. Nasal allergy and atmos- pheric pollution. Int J Pediatr Otorhinolaryngol 1999;49:257-60.

4. Hansen I, Klimek L, Mosges R, Hormann K. Mediators of inflammation in the early and the late phase of allergic rhinitis. Curr Opin Allergy Clin Immunol 2004;4:159-63.

5. Salib RJ, Drake-Lee A, Howarth PH. Allergic rhinitis: past, present and the future. Clin Otolaryngol 2003; 28: 291-303.

6. Wu CN. Safety and anti-inflammatory activity of curcumin: A component of turmeric (Curcuma longa). J Altern Complement Med 2003;9:161-8.

7. Bharti AC, Donato N, Singh S, Aggarwal BB. Curcumin (diferuloylmethane) down-regulates the constitutive activation of nuclear factor- $\kappa B$ and $I \kappa B \alpha$ kinase in human multiple myeloma cells, leading to suppression of proliferation and induction of apoptosis. Blood 2003;101:1053-62.

8. Gagliardo R, Chanez P, Mathieu M, Bruno A, Costanzo G, Gougat C, et al. Persistent activation of nuclear factor- $\kappa B$ signaling pathway in severe uncontrolled asthma. Am J Respir Crit Care Med 2003;168:1190-8.

9. Palit G, Singh SP, Singh N, Kohli RP, Bhargava KP. An experimental evaluation of anti-asthmatic plant drugs from ancient Ayurvedic medicine. Aspects Aller Appl Immunol 1983;16:36-41.

10. Godhwani S, Godhwani GL, Vyas DS. Ocimum sanctum: An experimental study evaluating its anti-inflammatory, analgesic and antipyretic activity in animals. J Ethnopharmacol 1987;21:152-63.

11. Kelm MA, Nair MG, Strasburg GM, Dewitt DL. Antioxidant and cyclooxygenase inhibitory phenolic compounds from Ocimum sanctum Linn. Phytomed 2000; 7:7-13.

12. Chakraborty A, Brantner AH. Study of alkaloids from Adhatoda vasica Nees. on their anti-inflammatory activity. Phytother Res 2001;15:532-44.

13. Dhuley JN. Antitussive effect of Adhatoda vasica extract on mechanical or chemical stimulation-induced coughing in animals. J Ethnopharmacol 1999;67: 361-5.

14. Dahanukar SA, Karandikar SM. Evaluation of anti-allergic activity of Piper longum. Indian Drugs 1984;21:377-83.

15. Nosal'ova G, Mokry J, Hassan KM. Antitussive activity of the fruit extract of Emblica officinalis Garetn. (Euphorbiaceae). Phytomed 2003;10:583-9.

16. Bhattacharya A, Ghosal S, Bhattacharya SK. Antioxidant activity of tannoid principles of Emblica officinalis (amla) in chronic stress induced changes in rat brain. Indian J Exp Biol 2000;38:877-80.

17. Sabu MC, Kuttan R. Antidiabetic activity of medicinal plants and its relation ship with their antioxidant property. J Ethnopharmacol 2002;81:155-60.

18. Kiuchi F, Iwakami S, Shibuya M, Hanaoka F, Sankawa U. Inhibition of prostaglandin and leukotriene biosynthesis by gingerols and diarylheptanoids. Chem Pharm Bull 1992;40:387-91.

19. Seo WG, Pae HO, Oh GS, Chai KY, Kwon TO, Yun YG, et al. Inhibitory effects of methanol extract of Cyperus rotundus rhizomes on nitric oxide and superoxide productions by murine macrophage cell line RAW 264.7 cells. J Ethnopharmacol 2001;76:59-64.

20. Mitra SK, Gopumadhavan S, Venkataranganna MV, Anturlikar SD. Antiasthmatic and antianaphylactic effect of E-721B, a herbal formulation. Indian J Pharmacol 1999;31:133-7.

21. Sengupta K, Kolhapure SA. Evaluation of efficacy and safety of HK-07 tablets in upper and lower respiratory tract allergic diseases in children. Med Update 2004;12:37-46.

22. Armitage AK, Boswood J, Large BJ. Thioxanthines with potent bronchodilator and coronary dilator properties. Br Pharm Chemother 1961;16:59-76.

23. Marone G, Casolara V, Patella V. Florio G, Triggiani M. Molecular and cellular biology of mast cells and basophils. Int Arch Allergy Immunol 1997:114:20717.

24. Schroeder JT, MacGlashan DW Jr, Subotka K, White JM, Lichtenstein LM. IgE-dependent IL-4 secretion by human basophils. The relation ship between cytokine production and histamine release in mixed leukocyte cultures. J Immunol 1994;153:1808-17.

25. Burrows B, Martinez FD, Halonan M, Barbee RA, Cline MG. Association of asthma with serum IgE levels and skin test reactivity to allergens. $\mathrm{N}$ Engl $\mathrm{J}$ Med 1989:32:271-7. 